\title{
The Sociosemiotic Approach and Translation of Fiction
}

\author{
A.R. Fatihi
}

\begin{abstract}
Translation and to be precise, the very act of language use is rooted in social mores and values. Hence meaning is not base generated in the dictionary but in the world around -- where the speech act takes place. Translation theory, as it is, has benefited from different theoretical developments in the domain of language studies, viz. transformational grammar, semantics, information theory, anthropology, semiotics, psychology, and discourse analysis. But when two creative genres of language use come face to face the issue of artistic justice is raised. No one theory can do that justice to fiction translation. We shall show in this paper that how stylistic analysis still stands out as a theory for literary enquiries. Here we engage in the decoding of the semiotic weaving of fictions through stylistic measures.
\end{abstract}

Key words: Translation, fiction, recent trends, stylistics, society, semiotics

During the past two or three decades, developments in the fields of transformational grammar, semantics, information theory, anthropology, semiotics, psychology, and discourse analysis have exerted great influence on general translation theory, enabling the discipline to broaden the areas of investigation and to offer fresh insights into the concept of correspondence on transference between linguistic and cultural systems. The traditionally much debated dichotomy between literal and free translation has been replaced by various linguistically informed modern distinctions, like Nida's "formal" versus "dynamic" correspondence, Catford's "formal correspondence" versus "textual equivalence," or Newmark's "semantic" as opposed to "communicative" translation. In general, more attention has been paid to the translation process and greater emphasis placed on "equal response" of the target 
language reader. Such new perspectives on theoretical front as well as the fairly extensive developments in specific interlingual contrastive studies have promoted considerably the understanding and mastery of the nature and skill of translation (Shen, 1996).

However, these are seen to be insufficient when applied to the translation of fiction. Translation of fiction has benefited very little from recent developments in linguistics. Shen Dan (1996) in particular emphasizes the necessity for applying literary stylistics to the translation of prose fiction, which is a significant contribution to the study of fiction translation, because some specific problems posed by translation of fiction such as "deceptive equivalence" can be rather effectively solved by the introduction of stylistic analysis. Shen Dan's attempt to introduce literary stylistics into translation of fiction is quite significant. However, the nature of fiction translation cannot be restricted in the literary stylistic analysis that considers style only as artistically or thematically motivated choices and focuses on the translation of foreground features of prose fiction. "Deceptive equivalence" is not the only problem that occurs in translation of fiction.

This paper intends to discuss the necessity of introducing the sociosemiotic approach to translation of fiction.

According to the sociosemiotic approach, the text is a semantic unit with meaning and function. It is a product in the sense that it is an output, something that can be represented in systematic terms. It is also a process in the sense of ongoing semantic choices, a movement through the network of potential meanings, with each set of choices constituting the environment for a further set. A novel/short story actually is a unity of meaning, style (how to convey meaning) and function (why to convey meaning) which we cannot discuss separately.

The whole process involved in the translation of fiction is rather complicated, including encoding of the message by the prose 
fiction writer, and decoding and re-encoding of the message by the fictional translator. The message, including meaning, style and function, is what the prose fiction author wishes to convey through his/her fiction in the order of pragmatic level (intention of the author or the theme of the fiction), semantic level (choice of words), syntactical level (choice of sentence patterns, etc.) and discourse level (integrating the former three levels into the entire discourse). This is the process how the fiction writer encodes his/her message. However, how the translator decodes the message is in the reverse order. At first, the translator comes across the whole discourse of the prose fiction, and then he/she analyzes it at the syntactical, semantic and finally pragmatic levels. At the end, the translator perceives the message conveyed by the SL text. The most important thing is how the translator re-encodes the message he/she understands, which is the basis of the translating activity. The order is very similar to the fiction writer's encoding process, but the language employed is different.

The translation criteria deriving from the sociosemiotic approach are "correspondence in meaning and similarity in style and function," which turns out to be well suited to verify the quality of fiction translation. "Correspondence in meaning" is actually correspondence in designative meaning, linguistic meaning and pragmatic meaning; "similarity in style" is similarity in both authorial style and text style, "similarity in function" is similarity in the six functions advocated by Peter Newmark. The translation of meanings and reflection of styles and functions, therefore, should rely on both linguistic context and non-linguistic context, i.e. culture and society. A qualified translator should acquire language competence and cultural knowledge of both TL and SL, and take pains to reduce the loss and distortion in his/ her translation. Thus, the translation may achieve the translation criteria-correspondence in meaning and similarity in style and function.

The recognition of this very fact of the textual and contextual nature of translating have positive consequences for the 
understanding of translation as a whole, Based on the linguistic textual nature of translation and its relevance for translation practice, the paper attempts to show the results of an analytical study that has been carried out to show the Initiator's and Translator's communicative purposes in the original and the translated text of Abdus Samad's Urdu fiction khabon ka savera The focus of the paper is mainly upon the semantic dimensions of the "hyper text" a term used by Genette (1982)

I understand it [hypertextuality] as every relationship joining a B text (which I would call hypertext) to a previous A text (which I would call obviously hypotext) into which it incorporates itself in a way different from that of a commentary."(Genette 1982:11).

He further explains that transposition is the most important of all hypertextual practices and characterizes translation as follows:

"-Thus I arrange these elementary practices in an increasing level of intervention in the sense of the transformed hypotext or more precisely in an increasing level of the evident and assumed character of this intervention, by distinguishing basically two main categories: in principle purely formal transpositions which concern the sense only by chance or due to a non-investigated ill consequence as is well known for the case of translation (which is a linguistic transposition), and openly and deliberately thematic transpositions where the transformation of sense is evidently, even officially, part of the purpose."

According to Genette's definition, translation is characterized as a case of hypertextuality where hypertext (i.e. Source Language Text) and hypotext (Target Language Text) only differ formally, whereas the thematic component of the texts involved remains somehow unaltered. In all other hypertextual phenomena where thematic changes do occur we cannot talk about translation any more but about commentaries, text reductions, amplifications, splits., etc. It suggests that Translations are characterized by a double binding: on the one hand there is a binding to the Source Language 
Text and, on the other hand, there is a binding to the communicative conditions on the part of the receiver. This double binding should be the point of departure for establishing the concept of equivalence".

The best method to find out interlinguistic or intercultural differences in text type conventions is to carry out parallel text analyses or parallel text comparisons. The initial comparison involves the corresponding paratexts of SLT and TLT texts. In G. Genette's (1982:9) terminology a paratext includes text title, subtitle, intertitle, prefaces, postscripts, etc.; marginal notes, footnotes, final notes; epigraphs, illustrations, jacket, etc. We would say that paratexts are text structural features which may coincide between SL and TL texts belonging to the same text type. According to the translation strategy implemented by the translator some paratexts not present in the original may be required to be added in the translated text. For instance, when translating a literary text, the translator may decide to keep many culture-bound source language words by using a foreignizing translation strategy. In order to ensure that target language readers grasp at least some of the original's meaning, the translator may decide to include footnotes or final notes to facilitate the comprehension of strikingly unfamiliar terms due to cultural distance between the source language and target language communities. These added notes can have a descriptive or a more elaborate explanatory content.

To elaborate" this point further lets have a look at the passage from "Dawn of Dreams"

(1) "Don't cry. insha allah, we will meet again. "When surah Fatiha is recited in this manner, then separation is only temporary and dear ones are reunited. Don't cry, your tears will darken our path. Pull yourself together, have faith in God. Whatever He does, He does for the best. He is surely the best Judge of everything."

"Bhaiyya, I am leaving you in God's hands." 
"Our salam to Dulhabhai. Tell him not to forget his promise to visit us."

"Goodbye Apa... goodbye... alvida.

(2) Suddenly, everything was over. The news had been floating around for quite some time now. The newspapers were full of it, but no one really believed it. And like so many other rumours, people talked, and then forgot all about it. Even those who were its supporters, did not believe that it could actually be implemented. But it had really happened. The law had been passed, and now, like an epidemic, it was going to knock on people's doors in the dead of the night. Of course, no one knew what it was going to be like, but its inevitability had quickly taken root in people's hearts. The arrival of this news had unleashed chaos in the haveli. Men dreading terrible days ahead, were shuddering, communicating their fear to the women who were shedding un-controllable tears. Everyone thought about the majestic haveli, Its vast portions, its beautiful decor, expensive furnishing, the exquisite clothes and precious jewels, stoves in the kitchens that burned continuously, producing innumerable varieties of delicious food. Honour, pride, status, the family's aura of awe and grandeur, their carefree existence- nothing had changed as yet, but a subtle fading, a pallor shadowed it all. Everything looked the same, but one could see the unknown invisible hand inching slowly towards them that would rip and fling everything within moments, destroying everything. Senior employees who had arrived from the villages, sat silently, lost in thought. For a little while they would talk to each other in whispers, but the envelope of silence persisted unchanged, smothering their very being.

"I knew this would happen. In order to get rid of the English Sarkar, Gandhiji has encouraged these low-caste people. Now those fellows are going to dance on our heads."

Patwariji spoke, wiping the sweat from his forehead with a large, red, checked handkerchief. 
"Bade Sarkar is also on their side. I wonder how he can put up with all this. Do you know, Ragho Bhaiyya, I saw him squatting on the ground eating from a leaf plate with Dusadh the chamar. Now tell me, have we ever done a thing like that?

His zamindari wasn't going to last much longer, anyway,"

Gumashtaji responded.

"He has bitten off his own thumb. His father the old sarkar commanded such awe and respect. If anyone dared approach without prior permission, he would have the skin off the man's back. If he looked someone in the eye, the fellow would-wet his pants. Because of him, we enjoyed our share of authority. Bade Sarkar has already upset all of this. It would have been difficult to manage the zamindari in such a lenient atmosphere anyway," Patwariji further added.

'You know, Ragho Bhaiyya, that bloody domna used to bring a chicken to my house everyday. Then, overnight, he began to find excuses for not bringing one. I got him tied to one of the pillars at the lower court and clobbered him with my shoe. That brought the bastard to his senses; but look at Bade Sarkar's attitude - when the domna went to him to complain against me, you know what Bade Sarkar did?"

"What did he do?"

“Got him appointed as a sweeper at a minister's house! Now tell me, what about my authority, and who's going to listen to me now? "When that fellow comes to the village, he stands before me boldly and greets me. Doesn't even lower... 

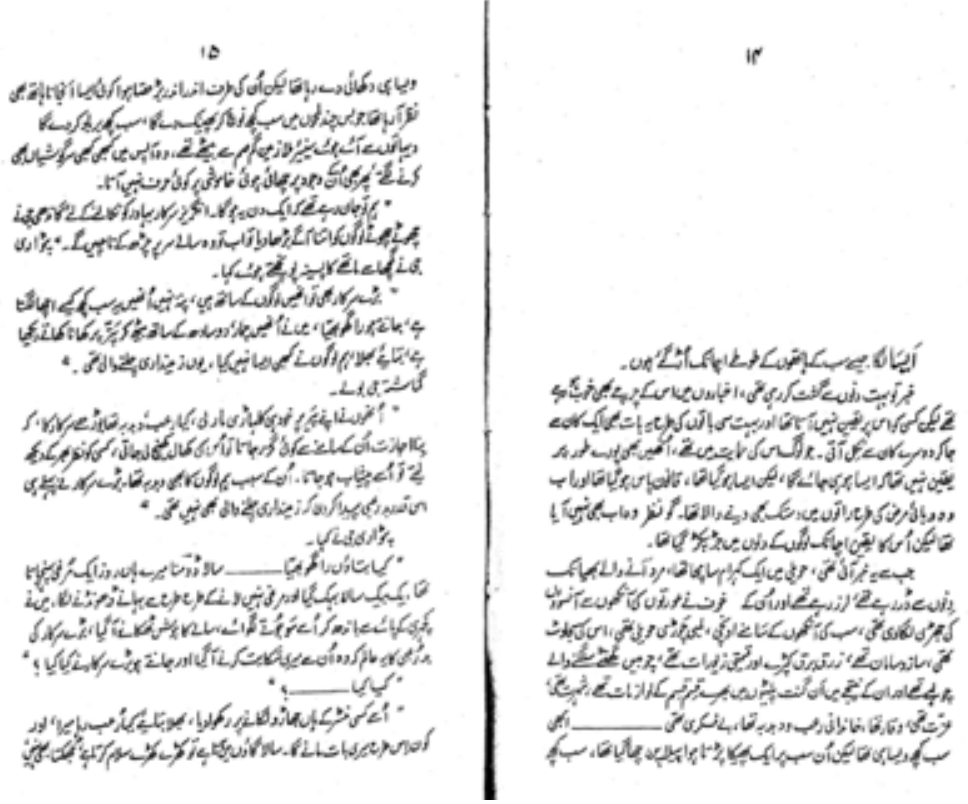

\section{Transliteration of the above Urdu text:}

aisaa lagaa jaise sab ke haathon ke tote achaanak uR gaye.

khabar to bahut dinon se gasht kar rahi thi, akhbaaron mein uske charche bhi khoob ho rahe the lekin kisi ko us par yaqeen naheen aataa thaaaur bahut si baaton ki tarah yah baat bhi eik kaan se jaakar doosre kaan se nikal aati. Jo log uski himaayat mein the, unhein bhi poore taur par yaqeen naheen tha ki aisaa ho jaayegaa, lekin aisaa ho gayaa thaa, qaanoon paas ho gayaa thaa aur ab wah wabaai marz ki tarah raaton mein dastak bhi dene waalaa thaa. go nazar wah ab bhi naheen aayaa thaa lekin uska yaqeen achaanak logon ke dilon mein jaR pakaR gayaa thaa.

Jab se yah khabar aayi thi, haweli mein eik kohraam saa machaa thaa, mard aane waale bhayaanak dinon se dar rahe the, laraz rahe the aur 
unke khauf ne auraton ki aakhon se aansuoun ki jhaRi lagaa di thi, sabke aakhon ke saamne oonchi, lambi chauri haveli thi, uski sajaawat thi, zaaz-o-saamaan the, zarq barq kapRe aur qeemti zewaraat the, chobees ghante sulagne waale choolhe the aur uske nateeje mein anginat pleton mein bhare qism qism ke lawaazemaat the, shohrat thi, izzat thi, waqaar thaa, khaandaani rôb wa dabdabaa thaa, befikri thi ---- abhi sab kuchh waisaa hi tha lekin un sab par eik pheeka paRtaa huaa peelaapan chhaa gayaa thaa, sab kuchh waisaa hi dikhaaii de rahaa thaa lekin unki taraf under under baRhtaa hua koi aisaa anjaanaa haath bhi nazar aa rahaa thaa jo bus chand lamhon mein sab kuchh noch kar phenk degaa, sab kuchh barbaad kar degaa, sab kuchh barbaad kar degaa.

dehaaton se aaye hue sinior mulaazemeen gumsum se baithe the, wah aapas mein kabhi kabhi sargoshiyaan bhi karne lagte, phir bhi unke wajood par chhaaii huii khaamoshi par koi harf nahee aataa.

"ham to jaan rahe the ki eik din yah hogaa. Angreiz sarkaar bahaadur ko nikaalne ke liye gandhi ji ne chhote chhote logon ko itnaa aage baRhaa diyaa to ab to wah saale sar par charH kar naachenge." Patwaari ji ne gamchhaa se maathe kaa paseena poonchhte hue kahaa.

"baRe sarkaar bhi to unheen logon ke saath hain, pataa naheen unhein yah sab kuchh kaise achchhaa lagtaa hai, jaante ho raaghu bhayyaa, main ne unhein chamaar, doosadh ke saath baiTh kar pattar par khaanaa khaate dekhaa hai, bataaiye bhalaa, ham logon ne kabhi aisaa naheen kyaa, yun zameendaari chalne waali thii." gumaashtaa ji bole.

" unhone apne pair par khud hi kulhaRi maar li, kyaa rŏb, dabdabaa thaa booRhe sarkaar kaa, ki binaa ijaazat unke saamne se koi guzar jaataa to uski khaal kheench li jaati, kisi ko nazar bhar ke dekh lete to usko peshaab ho jaataa, unke sabab hamlogon kaa bhi dabdabaa thaa. BaRe sarkaar ne pahle hi isqadar badrŏbi pidaa kar di ki zameendaari chalne waali bhi naheen thi." patwaari ji ne kahaa. 
"kyaa bataaun raaghu bhayyaa ---------- saalaa domnaa merey haan roz eik murghi pahunchaa thaa, ek baek saalaa bahak gayaa aur murghi naheen laane ke tarah tarah bahaane DhunDne laga, maine kachhari ke paaye se baandh kar usey sau joote lagwaaye, saale kaa hosh Thikaane aa gaya, baRe sarkaar ki badrŏbi yah aalam ki wah unse meri shikaayat karne aa gayaa aur jaante ho baRe sarkaar ne kyaa kyaa."

"kyaa kyaa -------- ?"

use kisi minister ke haan jhaaru lagaane par rakhwaa diyaa, bhalaa bataaiye kyaa rŏb rahaa meraa, aur kaun istarah meri baat maanegaa.

In the passage number one the use of the terms like " Inshallah" , "Surah Fatiha", " bhaiyya", "dulha bhai" and "alvida" are strikingly unfamiliar terms for English readers due to the cultural distance between the source language Urdu and the target language English. According to the translation strategy discussed earlier some paratexts not needed and presented in the original was required to be added in the translated text.

When we pay attention to the second passage for further discussion and elaboration we discover that, Mehr Farooqui (1993) prefers to use the expression "suddenly everything was over" which roughly corresponds to "Aisa laga: jaise sab ke hathon ke tote achanak Ur gaye" The cultural connotation of "Tote Ur gaye" has not been captured in the expression "Suddenly everything was over". As we know, creative energy constitute a rich translation resource to the extent that they provide the translator with an accurate pool of words related to the topic of SLT and precise guidelines as to the TLT overall structure. In Mehr's translation we hardly find the use of paratext or metatext ( commentaries) in the translated text. In translation, metatexts can also be a very valuable resource in order to better understand the content and the importance of SLT. 


\section{Equivalence range}

Equivalence in translation does not mean absolute correspondence between SLT and TLT. In DTM, once the textualization process of SLT has taken place, the text is articulated in four dimensions mutually imbricated: pragmatic, semantic, syntactic, and semiotic. Both SLT and TLT must have the same textual dimensions, i.e. pragmatic, semantic, stylistic, and semiotic. The content of each dimension will vary from close resemblance to total differentiation. If TLT is to be considered a translation of SLT, then there should be some strong link between them: the original's communicative intention should remain somehow unaltered, the content of TLT may vary if the target language linguistic and cultural norms call for a modification in order to maintain the SLT's textualized intention, and the stylistic devices will vary as they are bound to the TL text and language typology. Any modification of the SLT's communicative purpose outside the above mentioned parameters will yield TLT which may have a hypertext-hypotext relationship, but which cannot be called translations proper. They will be adaptations, summaries, commentaries, etc., but not translations. Thus, by translation equivalence range we understand the degree of coincidence and discrepancy between the diverse SLT and TLT dimensions (pragmatic, semantic, stylistic, and semiotic), which keeps the closest resemblance at the pragmatic dimension and modifies the semantic, stylistic and semiotic dimensions accordingly. By definition the translation equivalence range allows for more than one right solution to particular translation problems and corroborates the fact that one single SLT can be translated by using different translation strategies ranging from more SLT adherence to more TL audience focus.

The present study has listed the main translation problems encountered, and it has classified them according to the textual dimensions, The irregularities and anomalies encountered during the study were classified according to the following parameters in each textual dimension: 


\section{Pragmatic dimension}

A crucial aspect in this dimension has to do with the modality markers which indicate if the SLT author 'expressed subjectivity' that ranges from practically zero presence to a strong presence, has been maintained, slightly altered or wholly modified in TLT, thereby changing one of the most important elements of SLT sender's intentionality. Two concepts worked out by House and Kasper (1981) to deal with the pragmatics of politeness markers in English and German prove very useful also in translatology pragmatics: downgraders and upgraders. Downgraders are defined as markers which play down the impact X's utterance is likely to have on Y "Upgraders are defined as - modality markers which increase the force of the impact an utterance is likely to have on the addressee." (House \& Kasper 1981:166, 169). In our discussion we would say that downgraders are text modality markers which play down the impact on SLT expression is likely to have on TLT readers; and upgraders are text modality markers which increase the force of the impact an SLT utterance is likely to have on the TLT addressees. As stated above with regard to the primacy of the textual pragmatic dimension, a translated text is said to be equivalent to the original basically if the SLT author's intention is maintained in the translating process and reproduced and perceived as such by the TLT readers. Thus the degree of faithfulness to the original, pragmatically speaking, will increase as the number of cases of downgrading or upgrading decreases or, ideally, approaches zero.

The followings are some of the examples of discrepancy between SLT and TLT at the pragmatic level:

\section{Upgrading}

ham to jan raahe the ye ek din hoga.. Angrez sarkar bahdur ko nikalne ke liye Gandhi ji ne chote chote logon ko itna age barha diya to ab to wo sale sar par charh kar nachenge patwari ji ne gamcha se mathe ka pasina ponchte hue kaha. 
"I knew this would happen. In order to get rid of the English sarkar, Gandhiji has encouraged these low-caste people. Now those fellows are going to dance on our heads."

Patwariji spoke, wiping the sweat from his forehead with a large, red, checked handkerchief

The translated passage is only an approximation of the original scene, allowing upgrading of the referent. The translator has made alteration in the image by using

"Those fellows" for "wo Sale", which is much more polite and acceptable in comparison of "wo sale"

Nevertheless the example below provide an example of downgrading.

kamre ki fiza bari maghmum thi. ghari ki tik tik udasi ka khamosh élan kar rahi thi sanson ki zero bam par soch o fikr ki badal chai hue the pas main baten bhi ho rahi thin lekin jumlon ki darmiyan jo fasle paida ho rahe the who bare gahre aur tarik the in faslon ki darmyan kisi ki munh se jo kuch bhi nikalta who dur tarik bhigi hui rat main waqt ka élan karte hue gajar ki waz ki tarah kisi jagte hue zahan par parta.

Kya khyal hai apa tumhara

main kya bata sakti hun ye is bat ki sakht mukhalif hain

The atmosphere in the room was oppressive and the ticking of the clock was like a mute declaration of gloom. There was so much tension it was difficult to breathe. Although they were conversing, every sentence uttered created dark and unfathomable distances. Whatever was said between pauses had the effect of a gong, announcing the hour on a dark wet night to a sleepless restless mind.

"Apa, what do you think. ..?" 
The Urdu reader moves within the same cultural frame work as the author. So the modes of address trigger similar connotation and association. As part of the source language culture competence the translator should be able to deduce most cultural association implied by the author. Still the modes of address used in translated text called up elements of meaning different from the ones activated in source language text. The communicative relevance of "ye" in Urdu is totally different from English "he" and therefore use of "he" for "ye" is an example of downgrading.

\section{Semantic dimension}

The most frequent problems encountered during the study appear in this dimension. They correspond to omissions, additions, complete change of meaning, semantic calque, change of focalization, and change of connector. The most frequent case reported in this dimension was complete change of cultural meaning of the original. It occurred because Mehr often had problems finding out the appropriate English equivalent. Let us see some examples. To some extent, sometimes Mehr opts for substituting one item for another, trying to smooth the idea conveyed by the Abdus Samad, but the result does not always succeed, since there is a change in the lexical meaning. For example let's scan the use of "pretending" in the translated text. According to Cambridge Dictionary of English, the word "pretending" means to believe as if something is true when you know it is not "Hence, when the translator uses pretending for "taslim" in the sentence "Alia khatun ne Afaque ko goya bara taslim kar ki us se jirah ki" she may be trying to convey that there is something true, although little. Moreover, still in regard to the equivalence at word level, other example resembles to deceive what the ST meant to convey. Thus, "sala", in the ST becomes "fellow" s in the TT. For me, the translation failed in choosing correct cultural terms. It would be more adequate to use "sala", because it sounds more natural. I suppose this is the best equivalent in English translation. Taking into consideration that in every language there are some borrowings that enter and become part of the lexicon of that language, in the TT we 
have the well-established borrowing pajama, that is now part of the TL lexicon

\section{Change of cultural meaning}

Ammi, I won't go to school," five year- old Afaque came out with his verdict.

"What's this? Why won't you go to school?"

"Just like that." Afaque replied carelessly.

'Well my son, I want to know why you won't go to school. Aalhya Khatun argud with Afaque, pretending to treat him like an adult.

"It's a horrible school."

"Don't talk like this, my son. Your school is very nice."

"You don $\mathrm{t}$ know, It is a horrible school, all the boys are dirty, the teachers, are dirty, the classroom is dirty, books..." dirty

Stop this ."You re being very naughty. Why do you call it dirty tell me.

How can I te11you Ammi, you won't believe it's a dirty school.

Afaque began to cry. Soon he was sobbing. Aliya pulled him to her lap and consoled him. After a while Afaque melted in the warmth of his mother's lap. When his sobs ceased his mother gave him sweets and fruit and diverted his thoughts to fun and games. When Afaque calmed down, she asked him

lovingly, Now tell me, my sweet, what is it, why is school so dirty?"

'Ammi, the boys tease me. They call me miyan. Everyone calls me 'miyan'."

"What's there to be upset about? Muslims are often addressed as 'miyan'. They are not teasing you. If someone refers to me as 'miyan', so what? It will make me happy':' 
"No Ammi, it's not just that. The other day they unzipped my pants and began to make fun of me."

Aliya was stupefied. "Didn't you complain to the teacher.

"The teacher laughed, and so did the headmaster. They

didn't punish anyone." Afaque began to cry again. Aliya was at a loss for words. She comforted Afaque and asked as gently as possible, ,. ,

"Son aren't there any other Muslims? I mean miyan boys in your school?"

"I don't know. I am the only 'miyan' in my class. AmmI, I won't go to school."

"If you won't go to school, then how will you learn or read all these lovely books? And if you can't read, how will you become a zamindar?" Aliya tried to pacify the child.

"No, I won't go, I don't want to be a zamindar. Why has Abbu put me in this school? I will never, never go to this school

Ammi main School nahin jaunga

en ye kya bat hui tum school kyun nahin jaoge

bas yun hi Afaque ne bahut la parwahi se jawab diya

Akhir main bhi to sunun tum school kyun nahin jaoge? Alia khatun ne Afaque ko goya bara taslim kar ki us se jirah ki

wo bahut ganda school hai

yun nahin bolte bete who bahut accha scool hai

Ap ko kya pata Who bahut ganda school hai us ki sab larke gande teacher gande class ganda kitaben

bas bas ab band karo tum bahut badmash ho gaye ho akhir who kis tarh ganda school hai Akhir main bhi to janun 
ab main ap ko kya bataun ammi ap manti hi nahin wo bahut ganda school hai Afaque rane laga us ki hichkiyan bandh gayin

Aliay khatun ne use god main utha liya aur cumkarne lagin muhabbat ki garmi pa kar Afaque kuch pighla hichkiyan band huin to Aliya khatun ne use mithaiyan din aur phal diye

aur phir khl kud ki bat nikal kar us ka dimagh susri taraf mor diya Afaque jab puri tarah apnea p main a gaya to unhon ne us se bare pyar se pucha ab bato mujhe bat kya hai who school tumhen kyun ganda lagta hai

Ammi janti hain whan ki larke mujhe miyan miyan kahte hain sab mujhe miyan miyan kah kat cirate hain.

to is main chirne ki kya bat hai miyan musalman ko kahte hain who sab tum ko chirate nahin hain agar kisi ne miyan kah diya to kya hua ham to bhai bahut khush honge nahin ammi who sirf miyan nahin kahte unhon ne mera pant khol diya aur katwa katwa kah kar sab hansne lage

Aliya khatun to sannate main agayin.

The sense of Urdu word "Badmash" in the original text is better conveyed by English word "impish" or "badly behaved". Naughty does not convey the sense of disobedience that is sought to be conveyed in the source language text. A little later, in the narrative we find the Urdu expression katwa is omitted in the translation. There is no mention of "Kata" (referring to act of circumcise) a derogatory expression generally used to tease Muslims in the translated text. By completely omitting this expression in translation an important aspect of Muslim identity and the tension between the two communities has been suppressed by the translator. Without any reference to its existence or any of its details, it has been completely omitted from the translated text. The expression contains vital information on various modes of societal tension and therefore even in restricted translation omissions on such scale is not justifiable. Since the original novel by Abdus Samad seeks to discuss the societal 
tension, the effect of such omission has to be examined.

Translation is not just a matter of decoding certain linguistic forms into meaning and encoding this into new forms. Translation goes beyond that. It is a complex mental process and involves a wide spectrum of decisions the translator has to make in order to achieve retextualisation for an ideal reader.

\section{Syntactic Dimension}

Concerning the grammatical equivalence, it may be said that in the ST, most verbs are in past tense form, while in the TT the same verbs are in the present tense form.

\section{1. tum bahut badmash ho gaye ho}

You are being very naughty

In some instances, the use of present tense seems inappropriate, but in others it seems adequate, since the text refers to results of a study in which they talk about actions and situations which happen repeatedly. Also, by applying the present tense in the $\mathrm{TT}$, the translator is trying to bring the reader closer to the content. Thus, we may be talking about an imaginary present time, in which the use of a fictional present appears to put the reader in the place of someone actually attending the events. In the ST, we may perceive that the marked term is the continuous, referring to the progress of the event. However, in the TT, the simple form is neutral. In relation to the progressive aspect was receiving, one could add that it lacks certainty with regard to the completeness of the event.

\section{Conclusion}

By browsing the whole text, it is clear that in most sections of the study, the Urdu text was longer than the English text. This led me to wonder if this is because Urdu words are longer or because, in Urdu, we tend to use more words to explain one thing. 
All in all, after analyzing the TT, I realized that the translator tried to follow as much as possible the ST, in form and content. It is important to find the closest equivalence, in order to transmit correct and complete information. So as to speak, it did not seem to interfere in the reader's comprehension of the text, maybe because the target audience does not care much about the natural flow of information. The new text should be read naturally, as if it were the original version, with no influence of the ST. Nevertheless, in the TT, there are parts in which we lose information, whereas in others we gain information.

As a whole, translation is an art that requires a great deal of effort on the translator's part in trying to adapt the source text to the culture and linguistic aspects of the TT being produced. And, even after having "finished" the translation, it is always open to improvement.

\section{REFERENCES}

Apel, F., 1983. Literarische Übersetzung. Stuttgart: J.B. Metzlerische Verlagsbuchhandlung.

Ben-Ari, N., 2002. - The Double Conversion of Ben Hur. A Case in Manipulative Translation. In Target 14:2, p. 263-301.

Benjamin, W., 1923. -Die Aufgabe der Übersetzung-. In R. Triedmann and H. Schweppenhäuser (eds) Gesammelte Schriften, Frankfurt: Suhrkamp, 1980.

Berman, A., 1984. Lépreuve de létranger : Culture et traduction dans lAllemagne romantique. Paris : Gallimard.

Biber, D., 1989. A Typology of English Texts. In Linguistics 27, 3-43.

Bolaños, S., 2001. Hacia un Modelo Traductológico Dinámico (MTD). En Forma y Función, No.14, Bogotá, Departamento de Lingüística, Universidad Nacional de Colombia. p.19-66. 
Bolaños, S., 2002. Equivalence Revisited: A Key Concept in Modern Translation Theory. En Forma y Función, No.15, Bogotá, Departamento de Lingüística, Universidad Nacional de Colombia. p.60-88.

Bolaños, S., 2003. Cómo traducir De la teoría a la práctica pedagógica. En Formay Función, No.16, Bogotá, Departamento de Lingüística, Universidad Nacional de Colombia. p.109-134.

Bolaños, S., 2004. Hacia una visión integradora de la traducción: propuesta del Modelo Traductológico Dinámico (MTD), en Forma y Función 17. p.89-106.

Bolaños, S., 2005. La traductología: "Un campo de estudios sin vías de comunicación”. In E. Rodríguez (ed). Didáctica de la traducción y la terminología. Cali: Facultad de Humanidades, Universidad del Valle. p. 61-87.

Eco, U., 2003. Dire quasi la stessa cosa. Esperienze di traduzione. Milano : RCS Libri S.p.A.bGenette, G., (1982). Palimsestes. La littérature au second degré. Paris : Éditions du Seuil.

Göpferisch, S., 1999. Paralleltexte. In M. Snell-Hornby, H. G. Hönig, P. Kußmaul, P.A. Schmitt (eds.). Handbuch Translation. Zweite verbesserte Auflage. Tübingen: Stauffenburg Verlag. p. 184-186.

Helbig, G., 1986. Entwicklung der Sprachwissenschaft seit 1970. Leipzig: VEB Bibliographisches Institut.

Hermans, T., 1999. Descriptive Translation Studies. In M. SnellHornby, H. G. Hönig, P. Kußmaul, P. A. Schmitt (eds.). Handbuch Translation. Zweite verbesserte Auflage. Tübingen: Stauffenburg Verlag. p. 96-100

House, J., 1997. Translation Quality Assessment. A Model Revisited. Tübingen: Gunter Narr Verlag.

House, J. \& G. Kasper, 1981. Politeness Markers in English and 
German. In F. Coulmas (ed). Conversational Routine. The Hague: Mouton, 157-185.

Kade, O., 1968. Grundfragen der Übersetzungswissenschaft. Beihefte zur Zeitschrift Fremdsprachen II. Leipzig: VEB Verlag Enzyklopedie.

Koller, W., 1993. Zum Begriff der eigentlichen' Übersetzung” In J. Holz-Mänttäri \& Ch. Nord. Traducere Navem. Festschrift für Katharina Reiß zum 70. Geburtstag. Heidelberg: Tempere. p. 49-63.

Ladmiral, J-R., 1993. Sourciers et ciblistes. In J. Holz-Mänttäri \& Ch. Nord. Traducere Navem. Festschrift für Katharina Reiß zum 70. Geburtstag. Heidelberg: Tempere. p. 287-300.

Reiss, K., 1971. Möglichkeiten und Grenzen der Übersetzungskritik. München: Max Hueber Verlag. Trad. ing. por Erroll F. Rhrodes, (2000). Translation Criticism \& The potentials and Limitations. Categories and Criteria for Translation Quality Assessment.. New York / Manchester, American Bible Society / St. Jerome Publishing.

Shveitser, A. D., 1988. Теория перевода. Статус. Проблемы. Аспекты. Москва: Наука, 1988.

Snell-Hornby, M., 1988. Translation Studies. An Integrated Approach. Amsterdam/Philadelphia: John Benjamins.

Toury, G., 1995. Descriptive Translation Studies and beyond. Amsterdam/Philadelphia: Johns Benjamins.

Venuti, L., 1998. The Scandals of Translation: Towards an Ethics of Difference. London \& New York: Routledge. 